\title{
Crisis of confidence in cardiothoracic trainees: National trends in the use of minimally invasive esophagectomy
}

\author{
Lauren J. Taylor, MD, and James D. Maloney, MD, Madison, Wis
}

\footnotetext{
From the Division of Cardiothoracic Surgery, Department of Surgery, University of Wisconsin, Madison, Wis. Disclosure: The authors reported no conflicts of interest.

The Journal policy requires editors and reviewers to disclose conflicts of interest and to decline handling or reviewing manuscripts for which they may have a conflict of interest. The editors and reviewers of this article have no conflicts of interest.

Received for publication Oct 12, 2020; accepted for publication Oct 13, 2020; available ahead of print Nov 12, 2020.

Address for reprints: James D. Maloney, MD, 600 Highland Ave, Madison, WI 53792 (E-mail: maloney@ surgery. wisc.edu).

JTCVS Open 2021;5:193-4

2666-2736

Published by Elsevier Inc. on behalf of The American Association for Thoracic Surgery. This is an open access article under the CC BY-NC-ND license (http://creativecommons.org/licenses/by-nc-nd/4.0/).

https://doi.org/10.1016/j.xjon.2020.10.006
}

Esophagectomy is highly morbid. Although overall survival has improved with centralization of care, postoperative morbidity has been quoted as approaching 60\%. ${ }^{1,2}$ However, a recent multicenter randomized controlled trial reported a $77 \%$ reduction in major complications with hybrid minimally invasive esophagectomy compared with an open approach. ${ }^{3}$ Furthermore, randomized data support lower pulmonary morbidity following minimally invasive esophagectomy. ${ }^{4}$ Despite these convincing data, a survey of recent cardiothoracic graduates suggested a crisis of confidence in performing minimally invasive esophagectomy. ${ }^{5}$ Trainees identified attributed poor operative exposure as a significant contributing factor. We sought to examine national trends in the use of minimally invasive esophagectomy, focusing on characteristics of the institutions at which these procedures are performed.

\section{METHODS}

We conducted a retrospective analysis using Medicare data on esophagectomies performed in the United States between 2016 and 2018. Data were organized by operative approach (open vs minimally invasive/hybrid and transhiatal vs Ivor Lewis). Descriptive statistics were used to assess operative technique based on hospital factors, including geographic region and classification as a teaching institution.

\section{RESULTS}

We examined 26,455 esophagectomies performed during the study period, $13,667(51 \%)$ of which were transhiatal. Overall, $58 \%$ of transhiatal esophagectomies and $63 \%$ of Ivor Lewis esophagectomies were performed minimally invasively. The use of minimally invasive surgery increased over time and was more common at nonteaching hospitals. In $2016,1246(58 \%)$ of the transhiatal procedures performed at nonteaching hospitals used a minimally invasive technique, compared with $50 \%$ of those performed at teaching hospitals. This finding persisted over time, with a minimally invasive approach representing $69 \%$ of transhiatal

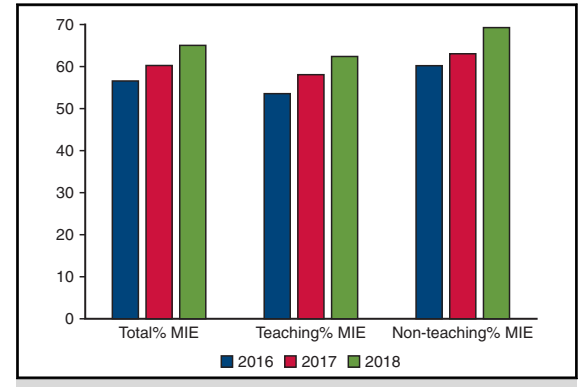

Minimally invasive esophagectomy at teaching and nonteaching facilities.

\section{CENTRAL MESSAGE \\ Although minimally invasive esophagectomy is becoming pervasive, use varies geographi- cally and is less common at teaching hospitals, contributing to a crisis of confidence for cardiothoracic trainees.}

See Commentary on page 195.

procedures performed at nonteaching hospitals and 59\% of those performed at teaching hospitals in 2018. A similar trend was found for Ivor Lewis esophagectomy (Figure 1). Operative technique varied geographically, with minimally invasive Ivor Lewis more common in the northeast US $(69 \%)$ compared with the western US (69\% vs 59\%).

\section{DISCUSSION}

Our data suggest that although minimally invasive esophagectomy is becoming more pervasive, its use varies geographically and is less common at teaching hospitals. These findings have important implications for patients and cardiothoracic trainees.

Promoting minimally invasive techniques is essential to ensure high-quality surgical care for esophageal cancer patients. Numerous studies have demonstrated substantial improvement in perioperative outcomes with an entirely minimally invasive or hybrid (laparoscopic abdomen, open chest) approach. In addition to significant reductions in major postoperative complications, Mariette and colleagues ${ }^{3}$ reported a $50 \%$ reduction in the risk of major 


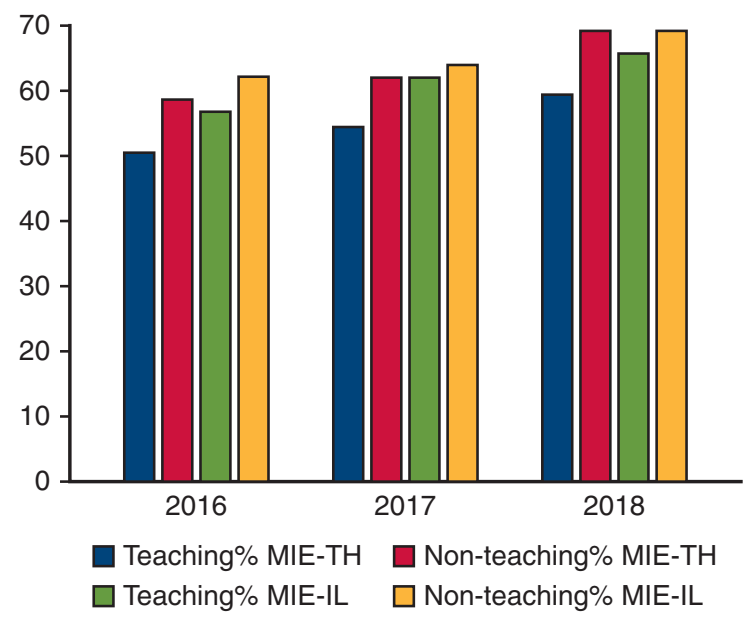

FIGURE 1. Percentage of minimally invasive esophagectomy over time, by facility (teaching vs nonteaching institution) and procedure type. $M I E$ $T H$, Minimally invasive transhiatal esophagectomy; MIE-IL, minimally invasive Ivor Lewis esophagectomy.

pulmonary complications, without compromising overall or disease-free survival. ${ }^{3}$ A database analysis reinforced these findings, with the use of laparoscopic, thoracoscopic, or robotic techniques associated with lower postoperative morbidity across 20 years of data without sacrificing oncologic outcomes. ${ }^{6}$ Similarly, hybrid esophagectomy has been associated with improved health-related quality of life, an essential metric for patients with poor prognosis at baseline. $^{7}$

According to survey data, cardiothoracic residents cite operative exposure during training as a major factor contributing to the likelihood of using a particular surgical technique in practice. ${ }^{5}$ Given that the average number of minimally invasive esophagectomies completed during training was 12 , it is no surprise that survey respondents reported that only $40 \%$ of esophagectomies performed in their current practice as junior attendings were done in a minimally invasive fashion-in contrast to well over twothirds of pulmonary lobectomies. This is even lower than the $60 \%$ rate of minimally invasive esophagectomy in our study, which may foreshadow a concerning shift toward the use of open techniques in new cardiothoracic graduates.

Although the path to proficiency in minimally invasive esophagectomy is not clearly defined, lessons from VATS lobectomy may offer valuable guidance. McKenna and colleagues suggest a minimum of 50 cases to address the learning curve-a requirement that may be challenging to achieve in some training programs. ${ }^{8}$ The development of simulation and assessment tools may allow trainees to develop manual and cognitive skills without dependence on clinical volume. ${ }^{9,10}$ These efforts appear to be paying off; a recent study by Boffa and colleagues ${ }^{11}$ reported that $86 \%$ of surveyed graduates who entered a dedicated thoracic practice considered themselves proficient in VATS lobectomy. ${ }^{11}$ In addition, our finding of differential use of operative approaches across teaching and nonteaching institutions-and geographic regions-offers an opportunity for skills transfer from the private sector in the form of workshops or possibly away rotations for trainees. Given the constraints of fellowship training, ongoing advanced training may need to be provided via mentorship of junior faculty after graduation. Without addressing this training deficiency, we are failing to prepare future cardiothoracic surgeons to provide high-quality cancer care.

Our study has several important limitations. Notably, we do not have information regarding the indication for surgery or the type of surgeon performing the procedures. Certainly there may be a bias toward patients with advanced-stage malignancy, necessitating an open approach at teaching institutions. However, it is critical to focus on how we train future cardiothoracic surgeons to ensure that patients receive the highest-quality care.

\section{References}

1. Dimick JB, Cattaneo SM, Lipsett PA, Pronovost PJ, Heitmiller RF. Hospital volume is related to clinical and economic outcomes of esophageal resection in Maryland. Ann Thorac Surg. 2001;72:334-9; discussion 339-41.

2. Merritt RE, Kneuretz PJ, D'Souza DM, Abdel-Rasoul M, Perry KA. An analysis of outcomes after transition from open to minimally invasive Ivor Lewis esophagectomy. Ann Thorac Surg. September 1, 2020 [Epub ahead of print].

3. Mariette C, Markar SR, Dabakuyo-Yonli TS, Meunier B, Pezet D, Collet D, et al. Hybrid minimally invasive esophagectomy for esophageal cancer. $N$ Engl J Med. 2019;380:152-62.

4. Biere SS, van Berge Henegouwen MI, Maas KW, Bonavina L, Rosman C, Garcia JR, et al. Minimally invasive versus open oesaphectomy for patients with esophageal cancer: a multicentre, open-label, randomized control trial. Lancet. 2012;379:1887-92.

5. Rothenberg PE, Hughes BD, Amirkhosravi F, Onaiwu BP, Okereke IC. Factors during training which predict future use of minimally invasive thoracic surgery. Ann Med Surg (Lond). 2018;35:149-52.

6. Meredith KL, Maramara T, Blinn P, Lee D, Huston J, Shridhar R. Comparative perioperative outcomes by esophagectomy surgical technique. J Gastrointest Surg. 2020;24:1261-8.

7. Mariette C, Markar S, Dabakuyo-Yonli TS, Meunier B, Pezet D, Collet D, et al. Health-related quality of life following hybrid minimally invasive versus open esophagectomy for patients with esophageal cancer, analysis of a multi-center, open-label, randomized phase III controlled trial: the MIRO trial. Ann Surg. 2020;271:1023-9.

8. McKenna RJ Jr. Complications and learning curves for video-assisted thoracic surgery lobectomy. Thorac Surg Clin. 2008;18:275-80.

9. Meyerson SL, LoCascio F, Balderson SS, D'Amico TA. An inexpensive, reproducible tissue simulator for teaching thoracoscopic lobectomy. Ann Thorac Surg. 2010;89:594-7.

10. Jensen K, Petersen RH, Hansen HJ, Walker W, Pedersen JH, Konge L. A novel assessment tool for evaluating competence in video-assisted thoracoscopic surgery lobectomy. Surg Endosc. 2018;32:4173-82.

11. Boffa DJ, Gangadharan S, Kent M, Kerendi F, Onaitis M, Verrier E, et al. Selfperceived video-assisted thoracic surgery lobectomy proficiency by recent graduates of North American thoracic residencies. Interact Cardiovasc Thorac Surg. 2012;14:797-800. 